\title{
articles
}

\section{Increasing Profits in Service Production Through Performance Feedback That Reduces Cognitive Time Distortion}

\author{
Fabian von Schéele ${ }^{1}$, Natallia Pashkevich ${ }^{2}$ b , Darek M. Haftor $^{3} \otimes^{c}$ \\ ${ }^{1}$ Faculty of Social Sciences, Uppsala University, ${ }^{2}$ School of Social Sciences, Södertörn University, ${ }^{3}$ Faculty of Social Sciences, Uppsala University; \\ University of Economics and Human Sciences in Warsaw, Poland \\ Keywords: Cognitive time, Clock time, Learning curve, service performance management \\ https://doi.org/10.53703/001c.29808
}

\section{Journal of Small Business Strategy}

Vol. 32, Issue 1, 2022

\begin{abstract}
This paper contributes to resolving the infamous problem of service production inefficiencies, focusing specifically on service profitability. Two independent experimental laboratory studies show that the profitability of services can be increased using performance feedback that informs task-performing individuals about the accuracy of their temporal assessments of the service tasks they have performed. Reducing inaccuracy in these assessments simultaneously reduces costs and increases service production revenues, boosting service profitability. This effect of feedback on the accuracy of time assessment at work and service profitability is a novel contribution to the literature on the economics of service production.
\end{abstract}

\begin{abstract}
"The basic reason why the actor's definition of the situation differs greatly from the objective situation is that the latter is far too complex."

March and Simon (1958, p. 173)
\end{abstract}

\section{Introduction}

This paper provides the first ever empirical evidence that service profitability can be substantially improved with a particular kind of performance feedback. This specific kind of performance feedback refers to providing information on the accuracy of the time assessment of a performed work task to the individual who conducted the task. This feedback reduces time waste in relation to the contracted work time volume for a service. It thereby substantially improves the profit of service delivery.

The overwhelming majority of the workforce in developed countries conduct services for both organization-external receivers and organization-internal users (Berry \& Stuart, 2021; Salas-Vallina et al., 2018; Sawant \& Jain, 2017; Sørensen \& Holman, 2014; Turriago-Hoyos et al., 2016). Therefore, it is of considerable concern that both the profitability and the efficiency of services are lagging behind these measures in other sectors (Brown \& Dev, 2000; Grönroos \& Ojasalo, 2004; International Telecommunication Union, 2015; Rust \& Huang, 2012; Stuber, 1990). To deal with this challenge, several approaches have been proposed and evaluated. Examples include investment in workers' use of advanced digital technologies (Aral, Brynjolfs- son, \& Van Alstyne, 2012; Srivastava et al., 2019; Tambe et al., 2012), the use of sophisticated performance monitoring and rewards procedures (Aral, Brynjolfsson, \& Wu, 2012; Villeval, 2020), and the optimization of work designs (Netessine \& Taylor, 2007; Tan \& Netessine, 2019). The cited papers and other similar studies show that these measures may cause profitability gains, albeit relatively small ones of about 1\% to 3\% (e.g., Eggert et al., 2011).

A recent approach to conceiving service work profitability and efficiency is based on the relation between an individual worker's perception of the duration (cognitive time) of a given work event, and the actual clock time duration (physical time) of that event (von Schéele \& Haftor, 2014). This relation reveals a gap between the two temporal experiences. Theoretical estimations of this novel approach suggest that accounting for and, subsequently, reducing this temporal gap, which is inherent in service production, have the potential to reduce service work inefficiency by 5 to $20 \%$ and to increase service profitability substantially (von Schéele et al., 2019, 2020; von Schéele \& Haftor, 2018). Unfortunately, until now, only theoretical studies have articulated this opportunity to reduce service inefficiency and increase profitability by addressing this temporal gap. There is no empirical evidence that this gap can be controlled and reduced, in order to lower service inefficiencies and increase profitability. This limitation is the focus of this paper. More specifically, the overall purpose of this paper is to advance the current understanding of how the gap

\footnotetext{
a Box 513, SE-75120 Uppsala, Sweden, fabian.vonscheele@im.uu.se

b SE-141 89 Huddinge, Sweden, natallia@athaydes.com

c Box 513, SE-75120 Uppsala, Sweden

Corresponding author: darek.haftor@im.uu.se
} 
between perceived duration and clock duration can be reduced to increase the profitability of service production. To that end, the objective of this paper is to evaluate empirically the managerial technique of performance feedback, which is evaluated. The results of these experiments show that under certain conditions, the use of performance feedback reduces the temporal gap, inherent in any human service production. Therefore, this paper provides the first ever empirical evidence that providing performance feedback to task-performing individuals on their assessments of the duration of completed service tasks can be successfully used to increase the profit of service production. Thus, this research contributes to the literature on performance feedback, with a particular focus on feedback that informs individuals of their CTD magnitude.

The next section reviews the theory of cognitive time distortion and its economic effects. This review ends with an illustration of a practical example of a software service delivery that articulates the underlying level effect that cognitive time produces, which, in turn, generates non-linear and counterintuitive economic inefficiencies in service delivery. That constitutes as a justification of the present study's focus on the performance feedback, which will be briefly reviewed thereafter. These theoretical recalls enable us to design and execute two empirical studies, which test performance feedback's impact on cognitive time, and thereby its ability to reduce economic inefficiencies. The results of the two studies are then discussed, followed by practical and managerial implications. Concluding remarks are then provided, before ending with some limitations and opportunities for future research.

\section{Cognitive time distortion as a source of inefficiency}

A recent approach to conceiving service work economics is based on the relation between an individual worker's perception of duration (cognitive time) and the actual clock time (physical time understood as clock time). This relation between the two kinds of temporal accounts is termed cognitive time distortion, or CTD (von Schéele \& Haftor, 2014), and refers to the gap between those temporal accounts. ${ }^{1}$ Theoretical estimations suggest that accounting for the CTD has the potential to reduce service work inefficiency by at least 5 to $20 \%$ and increase profitability many times over. Hence, the potential of this new approach differs starkly from that of the existing approaches (von Schéele \& Haftor, 2018). The CTD approach recognizes that a key cost of service work is often the duration (time) that is contracted for the performance of work tasks, in the form of both customer-provider contracts and provider-employee contracts (Williamson, 1981). The contracted duration is the ordinary clock time. This clock time is based on physical time, which refers to the duration of physical processes in nature (Das, 1990; Hassard, 1989). Contemporary approaches to the per- formance management of individual workers operate on the assumption that work time is monolithic and equals physical time (Aral, Brynjolfsson, \& Van Alstyne, 2012; Pierce et al., 2015; Tan \& Netessine, 2014). Remarkably, however, at least since the beginning of the 1990s, psychometric studies have provided clear empirical evidence that an individual's perception of a duration (i.e., the experience of time) for a given event has no constant relation with the physical duration or "clock time" of that event (Block \& Eisler, 1999; Levin \& Zakay, 1989; Nembhard \& Uzumeri, 2000). A review of the empirical literature shows that an individual's perception of 1 hour may range from 1.08 and 2.14 physical hours (von Schéele \& Haftor, 2018). Following von Schéele and Haftor (2014), cognitive time distortion (CTD) is denoted here as $\tau_{i}$ and is understood as the ratio between cognitive time $\left(t_{c}\right)$ and physical time $\left(t_{p}\right)$. It can be formalized thus:

$$
C T D: \tau_{i}=\left(t_{c} / t_{p}\right)_{i}
$$

The operationalization of CTD focuses on measuring a deviation of cognitive time in relation to physical time for the same given event, denoted in Eq. 1 as $i$. This event may be a work activity, a work task, a work process, a project, or a service contract. Both $t_{c}$ and $t_{p}$ must therefore refer to the same event, $i$, in order to establish a precise meaning of the CTD.

The practical experience of CTD is illustrated here with a software engineer who reports conducted work when leaving the office for the day. Assume that, based on the engineer's perception of the work duration, the engineer reports having spent 1 hour and 30 minutes coding software for client A (i.e., cognitive time), while she actually spent 1 hour and 44 minutes (i.e., physical time). Applying Eq. 1 shows that this assessment of work time gives a CTD of 0.87 . Therefore, the engineer is leaking $13 \%$ of work time and hence giving time away for free, which generates economic inefficiencies and decreased service profitability. The radical inefficiency consequences of that time leakage are illustrated here by applying the profit equation accounting for CTD, as proposed by von Schéele and Haftor (2014). Profit, denoted by $\pi$, in its generic form, regards the total revenues (TR) after total costs (TC) are deducted, as expressed in Eq. 2:

$$
\pi=T R-T C
$$

As the key cost component of service production is the volume of human work time (Tan \& Netessine, 2014), a distinction is made here between the profits originating from tangible substances, such as goods and commodities, and the profits originating from irreversible time. The volume of commodities can be stored; the volume of time cannot. This distinction is expressed in Eq. 3:

$$
\pi=(T R-T C)_{\text {Time }}+(T R-T C)_{\text {Commodities }}
$$

The present focus is only on human work time, constituting service production (ignoring any commodities). Therefore, Eq. 2 can be re-written by adding the subscript of "Time"

\footnotetext{
1 Several reasons are suggested for the emergence of CTD. Among others, studies suggest that CTD may be caused by the individual's mental and physical well-being, age, or workload. The literature is inconclusive, however, regarding the main driver of CTD. See von Schéele and Haftor (2014) for an overview.
} 
to the profit, thereby indicating only profit originating from the volume of time, as expressed in Eq. 4 :

$$
\pi_{\text {Time }}=T R_{\text {Time }}-T C_{\text {Time }}
$$

The production of services typically occurs in the context of an economic organization, as do the time assessments by human workers. Therefore, CTD is present simultaneously and unconditionally in customer contracts, denoted by $\tau$, and employee contracts, denoted by $\delta$. Considering these two forms of CTD (i.e., revenue and cost) enables a distinction to be made between CTD in total revenues (TR) and CTD in total costs (TC), although both variables, $\tau$ and $\delta$, refer to the same service activity. While von Schéele and Haftor (2014) offer a formalism that accounts for both current account and fixed-price contracts, for illustrative reasons, the focus here is on the latter. Therefore, the assumption is that there is one fixed-price customer contract and one fixed-price employee contract. This situation is expressed in Eq. 5:

$$
\pi(\tau, \delta)_{\text {Time }}=p t_{\mathrm{vol}}\left(\frac{1}{\tau}-\left(v_{\mathrm{p}}\right) \frac{1}{\delta}\right)
$$

In Eq. 5, the profit, $\pi$, refers to the volume of time, as reflected by its subscript. It captures changes in time volume, with respect to customer contracts $\left(\frac{1}{\tau}\right)$ and employee contracts $\left(\frac{1}{\delta}\right)$. In Eq. $5, p$ specifies the market price for a service hour, while $v$ denotes the price quotient, which is the ratio between the hourly employee price and the hourly market price.

Recalling our software engineer, the CTD of 0.87 implies that the engineer delivered $13 \%$ more time than customers had actually contracted and reimbursed. This corresponds to an over-delivery of services to the customer by $13 \%$. With respect to the employment contract, the engineer was $13 \%$ less efficient than budgeted. Therefore, $\tau=1.13$ and $\delta=$ 0.87 , assuming a market price per time unit, $p$, of 100 and an employee price per time unit of 75 gives a price quotient of 0.75 . Applying a CTD of 0.87 to Eq. 5 would give the profit made by the engineer for a reported work assignment. In this calculation, we assume that the total time volume, $t_{\mathrm{vol}}$ corresponds to 1 hour. First, we calculate the profit as if there were no time distortion (i.e., CTD = 1):

$$
\pi(\tau, \delta)_{\text {Time }}=100 \times 1 \times\left(\frac{1}{1}-(0.75) \times \frac{1}{1}\right)=25
$$

This calculation shows that the service profit corresponds to 25 monetary units per hour, which is a trivial result. We now calculate the profit when the software engineer has a time distortion of 0.87 , as discussed earlier:

$$
\begin{aligned}
\pi(\tau, \delta)_{\text {Time }} & =100 \times 1 \times\left(\frac{1}{1.13}-(0.75) \times \frac{1}{0.87}\right) \\
& =100 \times(0.88-0.86) \\
& =2
\end{aligned}
$$

The profit of the service that was actually conducted rather than reported (i.e., the profit when CTD is considered) is 2 , which is not a trivial result. This is due to the lever effect derived from the interaction between CTD, customer contracts, and employment contracts. Thus, any CTD that is not equal to 1 creates disturbances that affect both costs and revenues simultaneously and therefore service profitability. This lever effect is further demonstrated later in the paper.

This illustration shows the non-linear and counterintu- itive effects of CTD on the economic performance of operations conducted by human actors in an economic organization. By accounting for the unconditional CTD, it is now possible to articulate the magnitude of unrealized profitability inherent in service operations conducted by humans. Until recently, this unrealized profitability had been ignored (von Schéele et al., 2019, 2020; von Schéele \& Haftor, 2014, 2018). While this articulation is crucial for the measurement and understating of service economics, it raises the following question: What measure can reduce the magnitude of an individual worker's CTD and thereby improve profit? Answering this question is the focus of the current paper. More specifically, this paper shows for the first time that the managerial technique of performance feedback can be used to enable these reductions. The two experimental studies presented here show that CTD can be controlled and reduced. The crucial value of performance feedback in reducing CTD and increasing service profitability is illustrated with the example of the software engineer at the end of the paper.

\section{Performance feedback and hypotheses}

The reduction of an individual's magnitude of CTD requires a change in an individual's ability to perceive the duration of a given event. To that end, research provides a set of techniques for an individual's performance management (Cequea et al., 2011; Clements-Croome \& Kaluarachchi, 2000; Davies, 2005; Hopp et al., 2009). Such techniques include performing task design and redesign (Humphrey et al., 2007; Parker et al., 2001; Sokoya, 2000), setting task performance goals (Krenn et al., 2013; Van Yperen et al., 2015), providing task training (Hopp et al., 2009; Kraiger, 2003; Singh \& Mohanty, 2012), mentoring (Norby et al., 2010), conducting work performance assessments and appraisals (Bouskila-Yam \& Kluger, 2011; DeNisi \& Murphy, 2017), and providing task performance feedback (Aguinis et al., 2012; Nielsen, 2014; Slowiak \& Lakowske, 2017 ) in relation to rewards and other external forms of compensation (Danish \& Usman, 2010; Petroni \& Colacino, 2008). To the best of our knowledge, however, there are no empirical evaluations of the ability of these performance management techniques to reduce CTD. That gap is addressed in this paper by examining the possibility of reducing CTD magnitude by performance feedback only.

\section{Performance feedback}

The present study does not focus on the identification of optimal behavior with regard to the reduction of an individual's level of CTD. Consequently, it does not focus on the identification of the optimal reduction of work inefficiencies. This study has an exploratory aim, focusing on the identification of whether CTD can be deliberately reduced at all in order to improve profit. Therefore, this research focuses on one key managerial technique to bring about behavioral change, namely performance feedback. Here, performance feedback is understood as an action to provide a task-performing individual with information regarding a performed task (Kluger \& DeNisi, 1996, p. 255). This feedback may include information on deviations from set task targets. A chief reason for this choice is that performance 
feedback is regarded as the single most powerful governance mechanism to stimulate behavioral change (Kluger \& DeNisi, 1996; Thaler et al., 2014). Moreover, there is inconclusive evidence of whether performance feedback can improve an individual's temporal assessments (Tobin \& Grondin, 2015). While some studies suggest that experience of conducting time assessments may result in learning that improves the accuracy of subsequent assessments of durations (Roy et al., 2008), other studies show no such effect (Boltz et al., 1998). This inconclusiveness is also addressed by the present paper.

\section{Intrinsic and extrinsic motivation}

Providing a task-performing individual with feedback containing information about the actually conducted behavior, including possible deviations from established targets, automatically induces mainly intrinsic motivation for conducting subsequent work tasks (Chesbrough, 2003; Hopp et al., 2009; Horwitz et al., 2003; Markova \& Ford, 2011; Thompson \& Heron, 2005). On the other hand, providing a task-performing individual with feedback containing information only on a performance reward offer induces mainly extrinsic motivation for conducting subsequent work tasks (Danish \& Usman, 2010; Petroni \& Colacino, 2008). These two kinds of feedback tend to be the most commonly used managerial practices (Gerhart \& Fang, 2015; Kuvaas et al., 2017). They are therefore considered here to mirror such managerial practices and are used to evaluate the ability of these practices to control and reduce an individual's magnitude of CTD. To the best of our knowledge, no studies have evaluated their ability to do so.

\section{Hypotheses}

Given the inconclusiveness of the existing studies discussed earlier, the following two hypotheses were evaluated in Study 1:

H1a Feedback that provides the task-performing individual only with information about the actual magnitude of CTD, in relation to a conducted task, reduces the CTD magnitude in the assessment of a subsequently performed task.

H1b Feedback that provides the task-performing individual only with information about a performance reward reduces the CTD magnitude in the subsequent assessment of a performed task.

Study 1 compares two modes of performance feedback. The first focuses on the activation of intrinsic motivation for behavioral change by feeding back information about the actual level of CTD. The second focuses on the activation of extrinsic motivation for behavioral change by providing information about a performance reward, which constitutes an incentive.

The results of Study 1 show that performance feedback that gives information about CTD (Group B) is more successful at reducing the magnitude of CTD than feedback that provides information about a performance reward (Group A). The results of Study 1 also suggest that there may be a learning effect where subsequent iterations of feed- back may incrementally augment the reduction in CTD magnitude. However, Study 1 was not designed to explore such a learning effect, so it included only five feedback iterations. Therefore, a second experiment, Study 2, was designed and conducted to confirm the results of Study 1 and to explore the character of such a learning curve. Study 2 therefore again evaluated Hypothesis $1 a$, as well as Hypothesis 2:

H2 For each subsequent iteration of feedback that provides the task-performing individual only with information about the actual magnitude of CTD, an additional reduction of that CTD magnitude is achieved in subsequent assessments of a performed task, until saturation is reached. At this point, no additional change is caused by subsequent feedback iterations.

Study 2 confirms both the effect of performance feedback as a means of reducing CTD magnitude (Hypothesis 1a) and uncovers some of the characteristics of the learning curve, showing that approximately 20 feedback iterations produce a saturation level (Hypothesis 2). Details of these two studies are now presented.

\section{Study 1: Comparison of two types of feedback mechanism}

Study 1 was used to compare two groups of individuals with regard to the reduction in CTD. Individuals in Group B were provided with feedback only on the magnitude of their CTD (i.e., the deviation between their cognitive time and the actual clock time). Meanwhile, individuals in Group A received feedback not on their CTD magnitude but on financial rewards as an incentive to reduce the CTD magnitude. Thus, Study 1 was used to compare two modes of performance feedback: the first activates mainly intrinsic motivation for behavioral change, and the second activates mainly extrinsic motivation for behavioral change.

\section{Sample}

A total of 63 students $(n=63)$ participated in this study. The students were enrolled in M.Sc. programs at the Royal Institute of Technology in Stockholm, Sweden. Individuals were asked to participate in the experiment in different lectures. Participation was voluntary. They were divided into two groups. Each group received different modes of feedback. Group A comprised 32 individuals, who were exposed to feedback on a performance reward offer. Group B comprised 31 individuals, who were exposed to feedback on their actual CTD magnitude. The gender distribution of the sample was $44.4 \%$ male and $55.6 \%$ female. Among the male students, 20 (31.7\% of the total sample) received reward information feedback, and 8 (12.7\%) received CTD performance feedback. Among the female students, 12 (19.1\%) received reward information feedback, and 23 (36.5\%) received CTD performance feedback. Table 1 shows the individual characteristics of each group.

\section{Materials, procedure, and measures}

Each individual performed an independent work task, which consisted of assembling a jigsaw puzzle. Their target 
Table 1. Descriptive characteristics of Group A and Group B individuals participating in Study 1

\begin{tabular}{|c|c|c|c|c|c|}
\hline & & & \multicolumn{2}{|c|}{ Gender } & \multirow[t]{2}{*}{ Total } \\
\hline & & & Male & Female & \\
\hline \multirow{4}{*}{ Feedback content } & \multirow[t]{2}{*}{ Group A: Reward information (reward = money) } & Count & 20.0 & 12.0 & 32.0 \\
\hline & & Percentage of total & 31.7 & 19.1 & 50.8 \\
\hline & \multirow[t]{2}{*}{ Group B: Performance information about CTD } & Count & 8.0 & 23.0 & 31.0 \\
\hline & & Percentage of total & 12.7 & 36.5 & 49.2 \\
\hline \multirow[t]{2}{*}{ Total } & & Count & 28.0 & 35.0 & 63.0 \\
\hline & & Percentage of total & 44.4 & 55.6 & 100.0 \\
\hline
\end{tabular}

was to do it in as little time as possible. The puzzle consisted of 60 pieces. Its complexity meant that it required at least 15 minutes of attention by an adult to assemble the whole puzzle. The aim was to imitate an information-intensive service task. The work task was conducted in a bright and airy room. The students did not have access to a clock. Each individual had to conduct five iterations of the work task. Each iteration was followed directly by the individual's own estimation of the time taken to conduct the task. The estimation was recorded by the individual on a sheet of paper, which was handed over to the leader of the experiment, who imitated the work supervisor. Only the individual and the experiment leader were present in the room.

Each work-task iteration was uniform. It was initiated with a signal from the supervisor who uttered the statement "Are you ready?" and followed directly with the statement "Start." After 2 minutes and 26 seconds, the supervisor uttered the statement "Stop!" followed by the individual's estimation of the duration. The individuals were not informed about the length of the time intervals. The individuals then received feedback in accordance with the information content for Group A and Group B. Each of the five work task iterations represented the same clock time duration (2 minutes and 26 seconds).

Work-task feedback with information on the performance reward offer was designed to imitate actual managerial practices with a bonus system consisting of a monetary reward. The individuals were orally informed that they would receive a reward of 500 Swedish krona if they gave the most accurate time assessment. That sum represented approximately $1 / 13^{\text {th }}$ of an average monthly budget for a student enrolled at a Swedish University at the time of the experiment. After each work-task assessment, the supervisor provided the task-performing individual with the following feedback information: "Good work! Well done! If you make an even better assessment next time, you may earn the bonus." The aim with the utterance "Good work!" was to imitate the practice of positive feedback, which is assumed to induce higher motivation than negative feedback.

Work-task feedback on the actual CTD performance was designed to imitate the individuals' potential learning and improvement of the conducted work task. Here, the improvement was in the accuracy of temporal assessment. After each assessment, the individuals received the following feedback: "Good work! Well done! However, your time assessment was XX\% too high / low." Here, "XX” was replaced with the actual number for the assessment. The word "high" or "low" was selected depending on the actual performance of the individual, depending on the true percentage of how much the time assessment deviated from the clock time. For each time interval, the corresponding physical time, subjective time assessment, and calculated magnitude of CTD were all recorded.

\section{Results of Study 1}

The experiment compared two modes of feedback aimed to reduce an individual's magnitude of CTD: feedback on a performance reward offer (Hypothesis $1 \mathrm{~b}$ ) versus feedback on actual CTD performance (Hypothesis 1a). The results of this study demonstrate that the two modes of feedback produce different impacts on the individual's ability to change temporal assessments of a conducted work task. Figure 1 shows the results for the five iterations of work tasks and associated temporal assessments. Individuals in Group B, who received information about their actual magnitude of CTD (Hypothesis $1 \mathrm{~b}$ ), had a significantly lower standard deviation than individuals in Group A, who received information about a performance reward offer (Hypothesis 1a). These results are supported by Levene's test of homogeneity of variance (see Table 2). Based on the mean values, the results do not provide evidence of whether feedback on performance reward offers or CTD performance feedback leads to a greater CTD reduction. A larger sample of individuals would probably be needed to show that.

The results in Table 2 demonstrate that as of work-task iteration 3 and the associated time assessment, there was a significant difference between the variance of the two groups employing the different modes of feedback. Individuals in Group B, who received information on actual CTD, had a significantly lower variance of CTD in their time assessment than individuals in Group A, who received information on the performance reward offer. This finding shows that CTD-related feedback reduces the variance of time assessments to less than half of the variance of the assessments with feedback on the performance reward offer.

Threats to construct validity, such as hypothesis guessing (Shadish et al., 2002), were minimized by informing individuals about the aim of the research at the end of the experiment. The internal validity was ensured by the short duration of the experiment. The students who participated in the experiment performed knowledge-intensive tasks and were representative of the target population. 
Table 2. Levene's test of homogeneity of variance

\begin{tabular}{|c|c|c|c|c|c|}
\hline & & Levene's Statistic & df1 & $\mathrm{df} 2$ & Sig. \\
\hline \multirow[t]{4}{*}{ Time assessment 1} & Based on mean & .240 & 1 & 61 & .626 \\
\hline & Based on median & .222 & 1 & 61 & 639 \\
\hline & Based on median with adjusted df & .222 & 1 & 60.160 & 639 \\
\hline & Based on trimmed mean & .242 & 1 & 61 & .624 \\
\hline \multirow[t]{4}{*}{ Time assessment 2} & Based on mean & .885 & 1 & 61 & .350 \\
\hline & Based on median & 1.021 & 1 & 61 & .316 \\
\hline & Based on median with adjusted df & 1.021 & 1 & 56.105 & .317 \\
\hline & Based on trimmed mean & .916 & 1 & 61 & .342 \\
\hline \multirow[t]{4}{*}{ Time assessment 3} & Based on mean & 8.765 & 1 & 61 & .004 \\
\hline & Based on median & 7.163 & 1 & 61 & .010 \\
\hline & Based on median with adjusted df & 7.163 & 1 & 43.496 & .010 \\
\hline & Based on trimmed mean & 8.265 & 1 & 61 & .006 \\
\hline \multirow[t]{4}{*}{ Time assessment 4} & Based on mean & 15.016 & 1 & 61 & .000 \\
\hline & Based on median & 12.473 & 1 & 61 & .001 \\
\hline & Based on median with adjusted df & 12.473 & 1 & 41.615 & .001 \\
\hline & Based on trimmed mean & 15.037 & 1 & 61 & .000 \\
\hline \multirow[t]{4}{*}{ Time assessment 5} & Based on mean & 21.232 & 1 & 61 & .000 \\
\hline & Based on median & 18.920 & 1 & 61 & .000 \\
\hline & Based on median with adjusted df & 18.920 & 1 & 39.294 & .000 \\
\hline & Based on trimmed mean & 21.089 & 1 & 61 & .000 \\
\hline
\end{tabular}

\section{Discussion of Study 1}

The results from Study 1 reveal important findings. First, for the first time ever, they provide empirical evidence that it is possible to reduce the magnitude of CTD generated retrospectively by an individual in relation to a performed work task. Second, the recent theoretical contributions to managerial economics that modify several econometric indicators to account for workers' CTD (von Schéele et al., 2019, 2020; von Schéele \& Haftor, 2014, 2018) are empirically confirmed for the first time. Third, this study not only shows that CTD can be controlled and reduced but also provides insight into the managerial practice that enables such a reduction. The results show that work-task feedback that gives actual CTD performance information to a task-performing individual does reduce CTD magnitude. Fourth, these results also contribute to the literature on performance feedback by offering the first ever empirical evidence that information on a task-performing individual's perceived time can be used in such a feedback mechanism (Aguinis et al., 2012; Nielsen, 2014; Slowiak \& Lakowske, 2017). Fifth, this study's results show that the feedback mechanism that provides information on a performance reward offer does not change the performing individual's CTD magnitude. Previous studies are inconclusive regarding whether such a feedback mechanism, by itself, is sufficient for successful control of an individual's work performance (Anseel et al., 2015). Sixth, this study also supports studies which show that feedback on a performance reward offer is not sufficient by itself to control behavioral change (Agui-

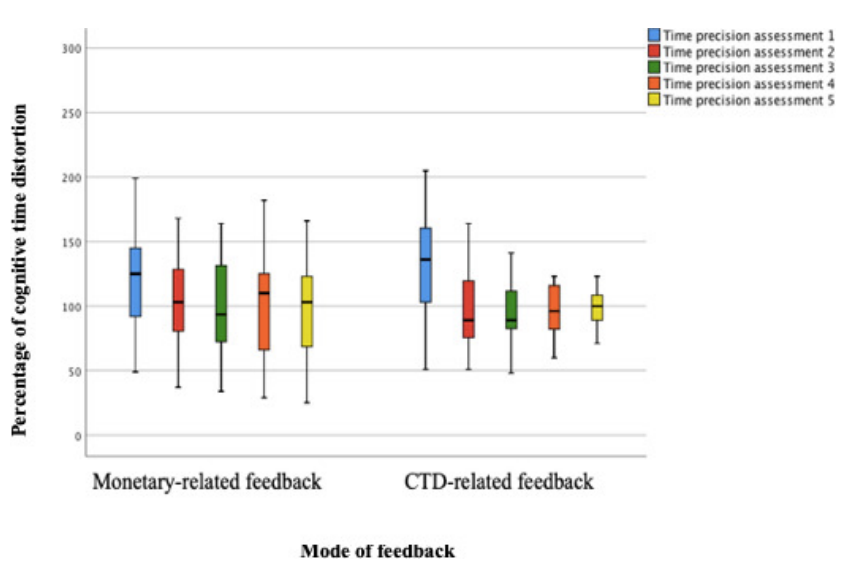

Figure 1. The left-hand plot shows the Group A subjects, who received performance reward information in their feedback. The right-hand plot shows Group B subjects, who received CTD performance information in their feedback.

The bold line in the box shows the mean values, while the upper and bottom box lines show the standard deviation values. The standard deviation values show that the CTD performance information fed back to students generated CTD reduction in subsequent time assessments. This reduction was not generated when performance reward information was provided in the feedback.

nis et al., 2012). This finding is reasonable because performance reward information does not inform the individual about actual performance. Thus, the individual lacks cognitive reference points for successful corrective adjustment of subsequent work-task performance. This finding brings this 
discussion to the seventh contribution of Study 1 . The data suggest that performance feedback that informs on actual CTD performance induces a learning curve (Womer, 1984). Accordingly, for each subsequent iteration of a given work task and the associated temporal assessment followed with performance feedback information, there is a step-wise improvement in the individual's assessment. Hence, there is an increased reduction of the CTD magnitude until a saturation level is reached. The Study 1 data only indicate such a pattern; the five iterations used in Study 1 were not sufficient to support this hypothesis. The need to test this indication (i.e., to test Hypothesis 2), together with the need to confirm the results of Study 1, which were based on a relatively small sample of individuals, motivated Study 2, which is reported below.

\section{Study 2: learning effect}

Study 2 had two key objectives. The first was to confirm or refute the results produced by Study 1 . Hence, Hypothesis 1a was tested. The second was to explore the learning curve suggested by Study 1 . Hence, Hypothesis 2 was tested. A task-performing individual conducted subsequent work tasks, each followed by supervisor feedback that informed the individual about the actual time assessment performance in relation to the target. Here, the learning effect refers to the phenomenon whereby each subsequent time assessment is improved because the individual learns to conduct these assessments more accurately.

\section{Sample}

This experiment included eight participating MBA students $(n=8)$ from Linnaeus University in Sweden. Individuals were asked to participate in the experiment during a lecture. They volunteered to do so freely. Four individuals were men and four were women. Their mean age was 32 years. All individuals had a bachelor's degree and five or more years of professional work experience. All eight individuals participated in the two subsequent experimental tests included in Study 2 .

\section{Materials, procedure, and measures}

Each individual conducted retroactive time assessment individually in a large, bright, quiet room. The individual had no access to a regular clock. Only the individual and the supervisor were in the room. Two kinds of assessments of duration were conducted by each individual: Session A and Session B. During Session A, the individual conducted 20 iterations of assessments of duration, without receiving any feedback whatsoever (hence, no CTD-related information). There was a 5-second pause between each iteration. After Session A ended, Session B was conducted immediately. The individual conducted 20 iterations of assessments of duration. In this case, each assessment was followed directly by the supervisor's feedback on the magnitude of CTD (i.e., the deviation between the actual clock time duration and the individual's assessment of that duration). The first 20 assessments (Session A) constituted both a calibration and a control for the subsequent 20 assessments (Session B).
The experiment in Study 1 used a static time frame for each individual's assessment with a given start and end. By contrast, the experiment in Study 2 used a dynamic time frame for assessment. Only the start was given. For each assessment, a randomly selected duration was chosen by the supervisor. This duration was always in the interval between 2 and 3 minutes. Hence, the duration of this experiment varied. At the start of each iteration, the supervisor slowly and clearly uttered a message with the selected duration, communicating it to the individual who performed the assessments. An example of this message was " 2 minutes and 33 seconds." After a 3-second delay, the supervisor signaled the initiation of the duration by uttering the word "Start." The individual then made the temporal assessment. When the individual perceived that the given duration had passed, the individual uttered the message "Stop," and the time was clocked by the supervisor. The supervisor used two stop clocks: one that measured the randomly selected time frame that was given to the individual (the physical time) and one that measured the duration assessed by the individual (the cognitive time). Both durations were recorded on a dedicated sheet of paper for each individual. This procedure was conducted for the first 20 iterations of the assessments by the individual.

Session B consisted of another 20 iterations using a similar procedure with one key modification: the inclusion of performance feedback. This feedback was given after each time assessment had been conducted and uttered by the individual to the supervisor. The supervisor then informed the individual of the deviation between the duration that was initially given to the individual and the individual's actual assessment, as measured by the supervisor (the CTD). This information was uttered in the following format: "Your assessment is XX seconds too short / long." Here, "XX" denotes the actual deviation for that individual, while the term "short" or "long" was selected depending on the direction of the individual's actual deviation.

\section{Results of Study 2}

Statistical process control was used to analyze the data collected from this experiment (Fitzsimmons et al., 2014). This method is appropriate to support statistical measures collected over time and to identify whether the process has common cause variation (Benneyan, 1998). Control charts help to monitor time assessment variation over time. Figure 2 presents a control chart with the data collected in the first type of assessment (Session A) and the second type of assessment (Session B). The horizontal axis shows the number of the iteration corresponding to each time assessment, and the vertical axis shows the actual percentage of CTD.

In Session A, without CTD-related feedback, the results reveal an average value (Avg.) of cognitive time distortion of $126 \%$. Control limits were identified. The lower control limit (LCL) was 69\%, and the upper control limit (UCL) was $183 \%$. Cognitive time distortion was expected to be within these limits. Figure 2 shows that, on average, individuals had an error of $26 \%$ of cognitive time distortion without CTD-related feedback and thus underestimated the actual time with their assessments. The data do not show any special cases outside the control limits, demonstrating that the 


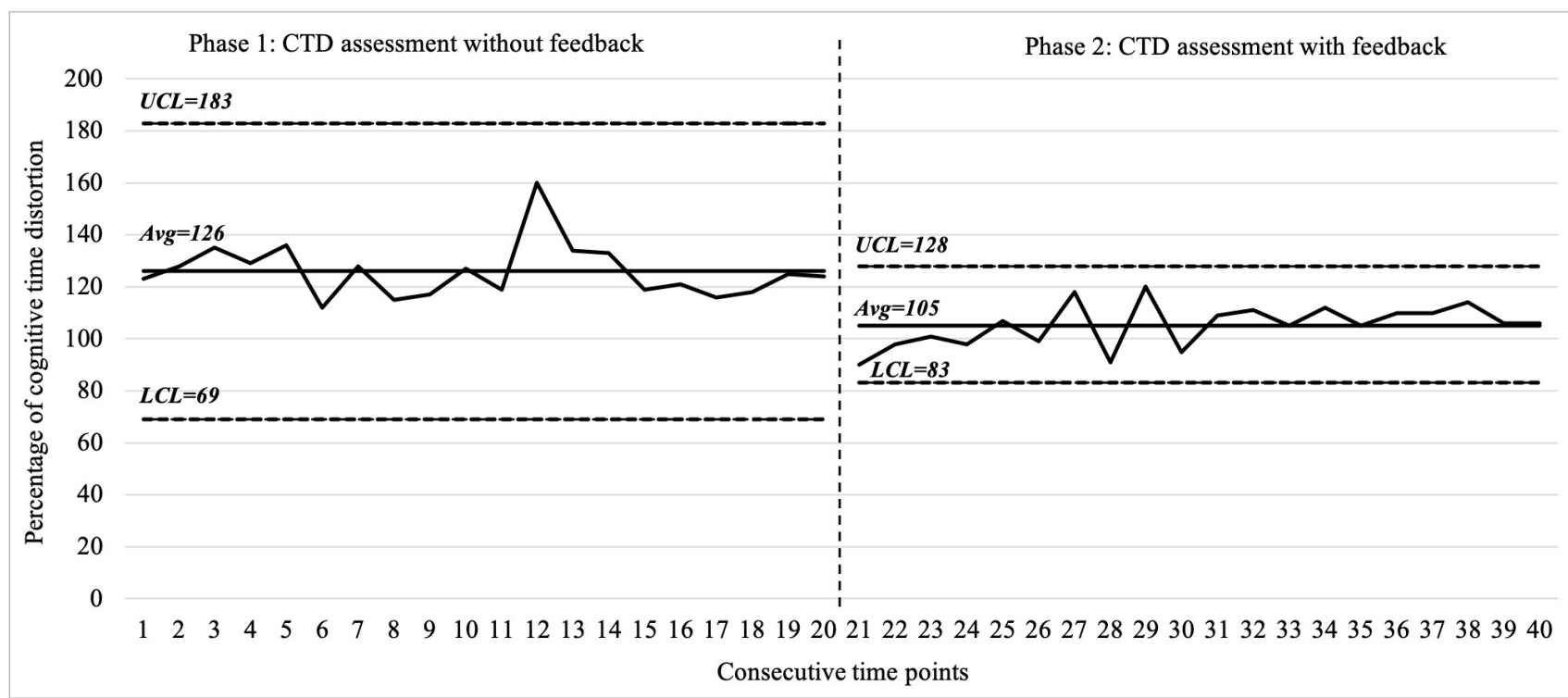

Figure 2. Control chart for cognitive time distortion in Study 2

The left-hand plot shows Session A, with individuals performing temporal assessments without feedback. The right-hand plot shows Session B, with individuals performing temporal assessments with feedback on the performed CTD magnitude. The results in the right-hand plot (Session B) show a learning curve, which is absent in the left-hand side of the figure (Session A).

process of time assessment had common cause variation. Crucially, the data show that the individuals' time assessments did not improve with each iteration. Thus, no learning curve can be identified from the data.

During Session B, individuals' time assessments were accompanied with feedback on the performed CTD. Figure 2 shows that the average value (Avg.) of cognitive time distortion was $105 \%$ and was thus more accurate than in Session A. With respect to Session A, the time precision in Session B decreased, on average, by 21 percentage points. The control limits for Session B were $83 \%$ (LCL) and 128\% (UCL). The data do not show any special cases outside the control limits. Crucially, the range within the control limits in Session B significantly decreased with respect to Session A, meaning that the process of time assessment became more accurate, reducing the magnitude of CTD.

\section{Discussion of Study 2}

First, the results of Study 2 demonstrate that the process of time assessment becomes more accurate with the presence of performance feedback that informs individuals about the actual CTD. This greater accuracy is shown by the average value and control limits. The results of Study 2 offer the first support for the assertion that performance feedback on performed CTD leads to learning. In subsequent iterations, the individuals' assessments follow a learning curve with regard to retrospective temporal assessment. Hence, this result supports Hypothesis 2. The results thereby support studies that confirm that the experience of time assessment improves subsequent time assessments (Roy et al., 2008), in contrast to studies that do not report such an effect (Boltz et al., 1998). Second, Study 2 confirms the results obtained in Study 1, namely that performance feedback that informs individuals about the performed CTD is an appropriate managerial technique to reduce the CTD magnitude (Hypothesis 1a). Third, this study also shows that an individual's iterative temporal assessments without nudging do not follow such a learning process. Study 2 had eight participants. A larger number of participants is required to replicate this experimental study with more consecutive time points to stabilize these results. The results of Study 2 must be taken in relation to Study 1 and the overall aim of this paper. This brings us to the overall discussion.

\section{Overall discussion \\ Theoretical implications}

For the first time, the two experimental studies presented here together provide empirical evidence that it is possible to control and reduce the magnitude of cognitive time distortion (CTD) due to an individual's retrospective time assessment. This is the key message of this paper. The second contribution of this paper is that the management practice of providing performance feedback that informs task-performing individuals of their CTD magnitude enables the reduction of that CTD. This is a novel contribution for two reasons. It is novel with regard to the reduction of CTD, and it is the first study to evaluate a form of performance feedback that provides information on the individual's time assessment of a conducted work task (Kluger \& DeNisi, 1996). Accordingly, this research also contributes to research on performance feedback that alters the content of information being fed to the individual exposed to the feedback (Anseel et al., 2015).

Third, managerial feedback to task-performing individuals that only offers performance rewards does not enable a reduction of the CTD. The reason for this finding seems to be that such information fails to induce learning by providing cognitive content as a reference point for subsequent corrective action. This cognitive content is provided by performance feedback that informs on the accuracy of past as- 
Table 3. Correspondence between the assumed values of CTD for customer contracts and employee contracts and values of the profit coefficient and the deviation of actual profit from the budgeted profit

\begin{tabular}{llll}
\hline $\begin{array}{l}\text { Values of CTD for customer } \\
\text { contracts }\end{array}$ & $\begin{array}{l}\text { Values of CTD for employee } \\
\text { contracts }\end{array}$ & $\begin{array}{l}\text { Profit } \\
\text { coefficient }\end{array}$ & $\begin{array}{l}\text { Deviation of actual profit from budgeted } \\
\text { profit (\%) }\end{array}$ \\
\hline 0.9 & 1.1 & 0.57 & +41.4 \\
\hline 1.0 & 1.0 & 0.40 & 00.0 \\
\hline 1.1 & 0.9 & 0.24 & -39.4 \\
\hline 1.2 & 0.8 & 0.08 & -79.2 \\
\hline 1.3 & 0.7 & -0.09 & -122.0 \\
\hline 1.4 & 0.6 & -0.29 & -171.4 \\
\hline
\end{tabular}

The price quotient is assumed to be $\nu=0.4$, indicating that the budgeted profit margin is $60 \%$.

sessments of duration by the task-performing individual.

Fourth, the study offers valuable evidence that performance feedback on CTD magnitude induces learning. This learning means that an iteration of subsequent work tasks with performance feedback augments the reduction of the CTD magnitude, until a certain saturation level is reached. This finding contributes not only to our understanding of the control of CTD but also to the inconclusive literature suggesting that there may be a learning effect with regard to temporal assessment. Study 2 shows that this learning effect is absent without performance feedback, whereas it is activated with performance feedback.

\section{Managerial implications}

The two studies presented here show that the magnitude of the CTD of service workers can be reduced with the deliberate use of performance feedback, which informs these workers about their CTD. Our software engineer, with a CTD of 0.87 , generated an actual profit of 2 monetary units. According to Eq. 5 in this paper, if the engineer's CTD were reduced to 0.9 , then the profit would become 8 monetary units. Furthermore, if the CTD were reduced to 0.95, then the profit would become 17 monetary units.

As CTD is not normally distributed (von Schéele \& Haftor, 2014), drawing conclusions based on the mean values and standard deviations in the two laboratory studies requires careful attention. To illustrate the generic effect of CTD performance feedback, we take the expression between the parentheses in Eq. 5, which may be regarded as a profit coefficient. This profit coefficient equals economically budgeted values, only in the rare situation where CTD equals 1 for customer contracts and employee contracts, which is virtually impossible (von Schéele \& Haftor, 2014). Table 3 lists a set of CTD values for both customer contracts and employee contracts, along with the corresponding profit coefficient and the consequent deviation of the actual profit from the budgeted profit. There is a dramatic deviation of actual profit (right column) from the budgeted profit. The profit coefficient varies dramatically with changes in the time volume of CTD.

These numbers show the crucial need for service managers to start paying attention to the distinction between the clock time, inherent in both customer contracts and employee contracts and workers' perceptions, assessments, and reporting of work durations. This paper shows that using CTD performance feedback in service worker management may generate radical reductions of service work inefficiencies. It also shows that CTD performance feedback is a more efficient managerial tool than worker incentives based on performance rewards, only because the latter do not reduce CTD reduction but instead create costs of governance.

\section{Concluding remarks}

Western economies are dominated by service production. The fact that service production lags behind goods production in terms of profitability and efficiency poses a challenge. Research has been busy finding means to deal with this challenge but has had limited success. It is therefore important to note that the results reported here provide a promising avenue to resolve this dilemma of service economies. The two laboratory studies presented here show the effects of iterations of performance feedback that gives task-performing individuals information on their assessments of the duration of performed service tasks. These iterations increase the accuracy of these temporal assessments and thereby reduce time leakage. As contracted time is the key costs of most service industries where human agents perform services, the economic effects of reduced time leakage are considerable. That magnitude is further extended by the unique character of time and service production - the steady, uninterrupted flow of contracted clock time. As time leakage influences both costs and revenues simultaneously, their interaction generates an exponential lever effect on the profit of services. This lever effect means that inaccurate time assessments have a dramatic impact on profit loss in service production. For the first time ever, this paper provides empirical evidence that performance feedback can control and reduce time leakage and thereby improve the profitability of service production by human agents.

This paper offers both bad and good news for service managers. The bad news is that virtually all service managers are unaware of cognitive time distortion and its harmful effects on their service economy; yet, the service operations they manage are unconditionally exposed to its harmful impact. The good news is that once they become 
aware of it, performance feedback is an inexpensive measure to reduce time leakage and thereby increase the profitability of their service production.

\section{Limitations and future research}

The research presented here has several limitations that should be acknowledged. These limitations constitute openings for further research. Both Study 1 and Study 2 had relatively few participants. This approach was suitable in relation to the aim of this paper, which was to explore whether CTD can be reduced with performance feedback. Because the results presented here are based on two independent studies, which support each other's results, our conclusion is firm: CTD can be reduced by performance feedback.

However, the detailed nature of CTD reduction requires further exploration by including larger groups of individuals in future experiments. Second, further studies must move on from an experimental setting into a real-life context by examining work in organizations to account for their operational complexities. The third limitation concerns the relatively short time frames used for assessment in the two studies presented here. Even though other independent studies (von Schéele \& Haftor, 2014) have shown that longer time frames also generate CTD, there is no evidence that longer time frames (e.g., 1 hour) can be reduced at all, or whether they require another kind of learning curve, as is the case with the shorter time frames evaluated here. This question also requires further exploration. Fourth, Study 1 shows that performance feedback on the performed CTD gives rise to CTD reduction. By contrast, feedback that only provides the individual with information on offers of performance rewards does not reduce CTD. Consequently, there is an opportunity to evaluate the two kinds of feedback information when used simultaneously. Research in this regard could investigate whether such a combination generates a faster and larger CTD reduction than performance feedback on the performed CTD. Fifth, this paper presents the first empirical evidence that performance feedback induces learning. This learning allows individuals to conduct more accurate time assessments, producing a learning curve in the form of a step-wise CTD reduction up to a saturation level. However, there is no knowledge available on the character of that learning curve in various performance contexts.

Finally, the question remains whether gender and a cultural context also condition an individual's perception of time, and thereby condition the temporal feedback mechanism, explored here, to control an individual's cognitive time distortion and thereby the worker productivity. Several studies indicate that such conditioning effects may emerge (Block et al., 1996; Carrasco \& Domínguez, 2015; Flaherty et al., 2005; Jaffe et al., 2012).

Submitted: September 22, 2021 CST, Accepted: November 02, 2021 CST 


\section{REFERENCES}

Aguinis, H., Gottfredson, R. K., \& Joo, H. (2012). Delivering effective performance feedback: The strengths-based approach. Business Horizons, 55(2), 105-111. https://doi.org/10.1016/j.bushor.2011.10.00 $\underline{4}$

Anseel, F., Beatty, A. S., Shen, W., Lievens, F., \& Sackett, P. R. (2015). How are we doing after 30 years? a meta-analytic review of the antecedents and outcomes of feedback-seeking behavior. Journal of Management, 41(1), 318-348. https://doi.org/10.1177/ $\underline{0149206313484521}$

Aral, S., Brynjolfsson, E., \& Van Alstyne, M. (2012). Information, technology and information worker productivity. Information Systems Research, 23(3), 849-867. https://doi.org/10.1287/isre.1110.0408

Aral, S., Brynjolfsson, E., \& Wu, L. (2012). Assessing three-way complementarities: Performance pay, monitoring and information technology. Management Science, 58(5), 913-931. https://doi.org/10.1287/mns c. 1110.1460

Benneyan, J. C. (1998). Use and interpretation of statistical quality control charts. International Journal for Quality in Health Care, 10(1), 69-73. https://doi.or $\mathrm{g} / 10.1093 /$ intahc/10.1.69

Berry, L. L., \& Stuart, B. (2021). An "essential services” workforce for crisis response. Journal of Public Policy \& Marketing, 40(1), 92-93. https://doi.org/10.1177/07 43915620928111

Block, R. A., Buggie, S. E., \& Matsui, F. (1996). Beliefs about time: Cross-cultural comparisons. The Journal of Psychology, 130(1), 5-22. https://doi.org/10.1080/0 0223980.1996.9914984

Block, R. A., \& Eisler, H. (1999). The complete bibliography on the psychology of time, 1839-1999 [Data set]. Montana State University, Department of Psychology.

Boltz, M. G., Kupperman, C., \& Dunne, J. (1998). The role of learning in remembered duration. Memory \& Cognition, 26(5), 903-921.

Bouskila-Yam, O., \& Kluger, A. N. (2011). Strengthbased performance appraisal and goal setting. Human Resource Management Review, 21(2), 137-147. http s://doi.org/10.1016/j.hrmr.2010.09.001

Brown, J. R., \& Dev, C. S. (2000). Improving productivity in a service business: Evidence from the hotel industry. Journal of Service Research, 2(4), 339-354. ht tps://doi.org/10.1177/109467050024003

Carrasco, C., \& Domínguez, M. (2015). Measured time, perceived time: A gender bias. Time \& Society, 24(3), 326-347. https://doi.org/10.1177/0961463x14538917

Cequea, M. M., Monroy, C. R., \& Bottini, M. A. N. (2011). The productivity from a human perspective: Dimensions and factors. Intangible Capital, 7(2), 549-584. https://doi.org/10.3926/ic.194

Chesbrough, W. H. (2003). A better way to innovate. Harvard Business Review, 81(7), 12-13.
Clements-Croome, D., \& Kaluarachchi, Y. (2000). Assessment and measurement of productivity. In D. Croome (Ed.), Creating the Prod Workplace (pp. 129-166). Routledge.

Danish, R. Q., \& Usman, A. (2010). Impact of reward and recognition on job satisfaction and motivation: An empirical study from Pakistan. International Journal of Business Management, 5(2), 159-167.

Das, K. (1990). The time dimension: An interdisciplinary guide. Praeger.

Davies, H. (2005). Productivity and the knowledge worker. Proceedings of the Queensland University of Technology Research Week International Conference, $1-16$.

DeNisi, A. S., \& Murphy, K. R. (2017). Performance appraisal and performance management: 100 years of progress? Journal of Applied Psychology, 102(3), 421-433. https://doi.org/10.1037/apl0000085

Eggert, A., Hogreve, J., Ulaga, W., \& Muenkhoff, E. (2011). Industrial services, product innovations, and firm profitability: A multiple-group latent growth curve analysis. Industrial Marketing Management, 40(5), 661-670. https://doi.org/10.1016/j.indmarma $\underline{\text { n.2011.05.007 }}$

Fitzsimmons, J. A., Fitzsimmons, M. J., \& Bordoloi, S. K. (2014). Service management: Operation, strategy, information technology. McGraw-Hill International.

Flaherty, M. G., Freidin, B., \& Sautu, R. (2005). Variation in the perceived passage of time: A cross-national study. Social Psychology Quarterly, 68(4), 400-410. htt ps://doi.org/10.1177/019027250506800407

Gerhart, B., \& Fang, M. (2015). Pay, intrinsic motivation, extrinsic motivation, performance, and creativity in the workplace: Revisiting long-held beliefs. Annual Review of Organizational Psychology and Organizational Behavior, 2(1), 489-521. https://do i.org/10.1146/annurev-orgpsych-032414-111418

Grönroos, C., \& Ojasalo, K. (2004). Service productivity: Towards a conceptualization of the transformation of inputs into economic results in services. Journal of Business Research, 57(4), 414-423. https://doi.org/1 $\underline{0.1016 / \mathrm{s} 0148-2963(02) 00275-8}$

Hassard, J. (1989). Time and industry psychology. In P. Blyton, J. Hassard, S. Hill, \& K. Starkey (Eds.), Time, work, and organization (pp. 13-34). Routledge.

Hopp, W. J., Iravani, S. M. R., \& Liu, F. (2009). Managing white - collar work: An operations - oriented survey. Production and Operations Management, 18(1), 1-32. $\underline{\mathrm{h}}$ ttps://doi.org/10.1111/j.1937-5956.2009.01002.x

Horwitz, F. M., Heng, C. T., \& Quazi, H. A. (2003). Finders, keepers? Attracting, motivating and retaining knowledge workers. Human Resource Management Journal, 13(4), 23-44. https://doi.org/1 0.1111/j.1748-8583.2003.tb00103.x 
Humphrey, S. E., Nahrgang, J. D., \& Morgeson, F. P. (2007). Integrating motivational, social, and contextual work design features: A meta-analytic summary and theoretical extension of the work design literature. Journal of Applied Psychology, 92(5), 1332-1356. https://doi.org/10.1037/0021-9010.92.5.1 $\underline{332}$

International Telecommunication Union. (2015). Measuring the Information Society Report 2015. http s://www.itu.int/dms_pub/itu-d/opb/ind/D-IND-ICTO I-2015-SUM-PDF-E.pdf

Jaffe, K., Mascitti, G., \& Seguias, D. (2012). Gender differences in time perception and its relation with academic performance: Non-linear dynamics in the formation of cognitive systems. arXiv preprint arXiv:1203.3954.

Kluger, A. N., \& DeNisi, A. (1996). The effects of feedback interventions on performance: A historical review, a meta-analysis, and a preliminary feedback intervention theory. Psychological Bulletin, 119(2), 254-284. https://doi.org/10.1037/0033-2909.119.2.25 $\underline{4}$

Kraiger, K. (2003). Perspectives on training and development. In W. C. Borman, D. R. Ilgen, \& R. J. Klimoski (Eds.), Handbook of Psychology (pp. 171-192). Wiley. https://doi.org/10.1002/047126438 5.wei1208

Krenn, B., Würth, S., \& Hergovich, A. (2013). The impact of feedback on goal setting and task performance. Swiss Journal of Psychology, 72(2), 79-89. https://doi.org/10.1024/1421-0185/a000101

Kuvaas, B., Buch, R., Weibel, A., Dysvik, A., \& Nerstad, C. G. L. (2017). Do intrinsic and extrinsic motivation relate differently to employee outcomes? Journal of Economic Psychology, 61, 244-258. https://doi.org/1 0.1016/j.joep.2017.05.004

Levin, I., \& Zakay, D. (1989). Time and human cognition: A life-span perspective (Vol. 59). Elsevier.

March, J. C., \& Simon, H. A. (1958). Organizations. Wiley.

Markova, G., \& Ford, C. (2011). Is money the panacea? Rewards for knowledge workers. International Journal of Productivity and Performance Management, 60(8), 813-823. https://doi.org/10.1108/1741040111118220 6

Nembhard, D. A., \& Uzumeri, M. V. (2000). Experiential learning and forgetting for manual and cognitive tasks. International Journal of Industrial Ergonomics, 25(4), 315-326. https://doi.org/10.1016/s0169-8141(9 9)00021-9

Netessine, S., \& Taylor, T. A. (2007). Product line design and production technology. Marketing Science, 26(1), 101-117. https://doi.org/10.1287/mksc.1060.0216

Nielsen, P. A. (2014). Learning from performance feedback: Performance information, aspiration levels, and managerial priorities. Public Administration, 92(1), 142-160. https://doi.org/10.1111/padm.12050

Norby, S. M., Karniski, L. P., Schmidt, D. W., \& Kohan, D. E. (2010). Mentoring for subspecialty training program directors: An unrecognized, unmet need? Journal of Graduate Medical Education, 2(2), 206-209. https://doi.org/10.4300/igme-d-09-00091.1
Parker, S. K., Wall, T. D., \& Cordery, J. L. (2001). Future work design research and practice: Towards an elaborated model of work design. Journal of Occupational and Organizational Psychology, 74(4), 413-440. https://doi.org/10.1348/096317901167460

Petroni, A., \& Colacino, P. (2008). Motivation strategies for knowledge workers: Evidences and challenges. Journal of Technology Management \& Innovation, 3(3), 21-32. https://doi.org/10.4067/s0718-2724200800010 $\underline{0003}$

Pierce, L., Snow, D. C., \& McAfee, A. (2015). Cleaning house: The impact of information technology monitoring on employee theft and productivity. Management Science, 61(10), 2299-2319. https://doi.o rg/10.1287/mnsc.2014.2103

Roy, M. M., Mitten, S. T., \& Christenfeld, N. J. (2008). Correcting memory improves accuracy of predicted task duration. Journal of Experimental Psychology, 14(3), 266.

Rust, R. T., \& Huang, M.-H. (2012). Optimizing service productivity. Journal of Marketing, 76(2), 47-66. http s://doi.org/10.1509/jm.10.0441

Salas-Vallina, A., Alegre, J., \& Guerrero, R. F. (2018). Happiness at work in knowledge-intensive contexts: Opening the research agenda. European Research on Management and Business Economics, 24(3), 149-159. https://doi.org/10.1016/j.iedeen.2018.05.003

Sawant, H., \& Jain, K. K. (2017). Issues related to knowledge in knowledge intensive organisations - a literature review. International Journal of Knowledge Management Studies, 8(3-4), 299-315. https://doi.or $\mathrm{g} / 10.1504 / \mathrm{ijkms.2017.087072}$

Shadish, W. R., Cook, T. D., \& Campbell, D. T. (2002). Experimental and quasi-experimental designs for generalized causal inference. Houghton Mifflin Company.

Singh, R., \& Mohanty, M. (2012). Impact of training practices on employee productivity: A comparative study. Interscience Management Review, 2(2), 74.

Slowiak, J. M., \& Lakowske, A. M. (2017). The influence of feedback statement sequence and goals on task performance. Behavior Analysis: Research and Practice, 17(4), 357-380. https://doi.org/10.1037/bar0000084

Sokoya, S. K. (2000). Personal predictors of job satisfaction for the public sector manager: Implications for management practice and development in a developing economy. Journal of Business Development Nations, 4(1), 40-53.

Sørensen, O. H., \& Holman, D. (2014). A participative intervention to improve employee well-being in knowledge work jobs: A mixed-methods evaluation study. Work \& Stress, 28(1), 67-86. https://doi.org/1 $\underline{0.1080 / 02678373.2013 .876124}$

Srivastava, S. K., Chandra, B., \& Srivastava, P. (2019). The impact of knowledge management and data mining on CRM in the service industry. In Nanoelectronics, circuits and communication systems (pp. 37-52). Springer Singapore. https://doi.org/10.10 07/978-981-13-0776-8_4

Stuber, G. (1990). The goods and services sectors: A longer-term perspective. Bank of Canada Review, Sept, 14-20. 
Tambe, P., Hitt, L. M., \& Brynjolfsson, E. (2012). The extroverted firm: How external information practice affect innovation and productivity. Management Science, 58(5), 843-859. https://doi.org/10.1287/mns c. 1110.1446

Tan, T. F., \& Netessine, S. (2014). When does the devil make work? An empirical study of the impact of workload on worker productivity. Management Science, 60(6), 1574-1593. https://doi.org/10.1287/mn sc. 2014.1950

Tan, T. F., \& Netessine, S. (2019). At your service on the table: Impact of tabletop technology on restaurant performance. Management Science. Published online November 8, 2019.

Thaler, R. H., Sunstein, C. R., \& Balz, J. P. (2014). Choice Architecture. In E. Shafir (Ed.), Behavioural Foundations of Public Policy (pp. 428-439). Princeton University Press. https://doi.org/10.2139/ssrn.253650 $\underline{4}$

Thompson, M., \& Heron, P. (2005). The difference a manager can make: Organizational justice and knowledge worker commitment. International Journal of Human Resource Management, 16(3), 383-404. http s://doi.org/10.1080/0958519042000339561

Tobin, S., \& Grondin, S. (2015). Prior task experience affects temporal prediction and estimation. Frontiers in Psychology, 6, 916. https://doi.org/10.3389/fpsyg.20 15.00916

Turriago-Hoyos, A., Thoene, U., \& Arjoon, S. (2016). Knowledge workers and virtues in Peter Drucker's management theory. SAGE Open, 6(1), 1-9. https://do i.org/10.1177/2158244016639631

Van Yperen, N. W., Blaga, M., \& Postmes, T. (2015). A meta-analysis of the impact of situationally induced achievement goals on task performance. Human Performance, 28(2), 165-182. https://doi.org/10.1080/ $\underline{08959285.2015 .1006772}$
Villeval, M. C. (2020). Performance feedback and peer effects. In Handbook of Labor, Human Resources and Population Economics (pp. 1-38). Springer International Publishing. https://doi.org/10.1007/97 8-3-319-57365-6_126-1

von Schéele, F., \& Haftor, D. M. (2014). Cognitive time distortion on the performance of economic organizations. Systems Research and Behavioral Science, 31(1), 77-93. https://doi.org/10.1002/sres.217 $\underline{3}$

von Schéele, F., \& Haftor, D. M. (2018). Temporal workload in economic organizations: a hidden condition of economic efficiency. Journal of Business Research, 88, 415-420. https://doi.org/10.1016/j.jbusr es.2018.01.042

von Schéele, F., Haftor, D. M., \& Pashkevich, N. (2019). Cognitive time distortion as a hidden condition of worker productivity. Journal of Business Research, 101, 591-596. https://doi.org/10.1016/j.jbusres.2018.11.00 $\underline{2}$

von Schéele, F., Haftor, D. M., \& Pashkevich, N. (2020). Cognitive time as a service price determinant: Hidden dynamics and price collapse. Journal of Business Research, 112, 248-253. https://doi.org/10.1016/i.jbus res.2019.10.056

Williamson, O. E. (1981). The Economics of organization: The transaction cost approach. American Journal of Sociology, 87(3), 548-577. http s://doi.org/10.1086/227496

Womer, N. K. (1984). Estimating learning curves from aggregate monthly data. Management Science, 30(8), 982-992. https://doi.org/10.1287/mnsc.30.8.982 